\title{
Agranulocytosis in a drug addict with recurrent Staphylococcus aureus septicaemia
}

\author{
WK Leung, Thomas YK Chan, Julian AJH Critchley
}

A 37-year-old male drug addict was admitted to hospital because of a swollen right lower limb for two weeks. He had been using his groin for injection of heroin. He had been hospitalised three times six months earlier because of left lower limb deep vein thrombosis with or without Staphylococcus aureus septicaemia. He discharged himself prematurely during the first admission. Apart from anticoagulants, he received intravenous cloxacillin, $500 \mathrm{mg} 6$-hourly, up to a total dose of 8.5-15.0 g during two of these admissions. Neutropenia was not seen. He had subsequently defaulted from follow-up.

On admission, he was febrile, with a blood pressure of $120 / 84 \mathrm{mmHg}$ and a heart rate of 100 beats/min. No cardiac murmurs were detected on auscultation of the precordium. No stigmata of infective endocarditis such as splinter haemorrhages were detected. His right lower limb looked swollen, with increased warmth and dilated superficial veins. Doppler ultrasound examination revealed a thrombus in his right femoral vein, which was treated by an intravenous heparin infusion, followed by warfarin. Blood cultures taken on admission grew $S$ aureus, which was sensitive to cloxacillin. From day 2, he was put on intravenous cloxacillin, $1 \mathrm{~g}$, 6-hourly together with netilmicin, $120 \mathrm{mg}, 12$-hourly. The dosage of cloxacillin was increased to $2 \mathrm{~g}$ 4-hourly on day 9 because of the poor clinical response. Although no vegetations were revealed on echocardiography, antibiotic therapy for four or more weeks was considered necessary in view of the history of recurrent septicaemia. His condition continued to improve until day 19 by which time he had received a total dose of $165 \mathrm{~g}$ of cloxacillin. He was then noted to have a high fever (figure) and a generalised maculopapular rash. His white cell count was $7.0 \times 10^{9} / 1(63 \%$ neutrophils) on day 20 but had dropped to $1.7 \times 10^{9} / 1$ ( $1 \%$ neutrophils) by day 22 (figure). There were no significant changes in red cell or platelet counts. When both antibiotics were stopped on day 23 , the fever rapidly subsided and the agranulocytosis gradually resolved. By day 25 , his white cell count was $2.6 \times 10^{9} / 1$ (neutrophils $29 \%$ ) and by day 27 , the agranulocytosis had completely resolved.

Chinese University of
Hong Kong, Prince of
Wales Hospital,
Shatin, New
Territories, Hong
Kong
Department of
Medicine
WK Leung
Department of
Clinical
Pharmacology
TYK Chan
JAJH Critchley

Accepted 1 June 1995

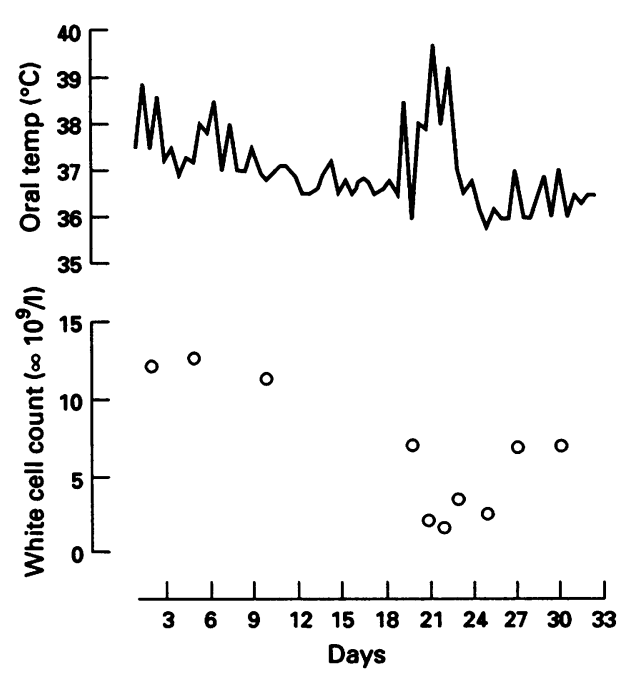

Questions

1 What is the most likely diagnosis?

2 What are the risk factors for this complication?

Figure Body temperature $\left({ }^{\circ} \mathrm{C}\right)$ and white cell counts (normal range 4.0-10.8 $\times 10^{9} / 1$ ) in a drug addict with $S$ aureus septicaemia treated with intravenous cloxacillin between days 2 and 23 


\section{Answers}

\section{QUESTION 1}

Cloxacillin-induced agranulocytosis. Cloxacillin, but not netilmicin, has been reported to cause agranulocytosis. This case is interesting in that two previous treatments with cloxacillin in doses of $2 \mathrm{~g}$ daily for up to eight days did not result in neutropenia. When he was treated with cloxacillin, $8 \mathrm{~g}$ daily, for 19 days, his neutrophil count suddenly dropped. Since cloxacillin-induced agranulocytosis was first recognised in $1978,{ }^{1}$ over 30 other cases have been reported. ${ }^{2-5}$

\section{Pathogenesis}

In the previously reported cases, ${ }^{1-5}$ both hypersensitivity reactions and direct toxicity have been suggested for the aetiology of the neutropenia. In our patient, the delayed onset of agranulocytosis and its relation to the use of a high dose of cloxacillin suggest a direct toxic effect on the bone marrow, but the presence of drug fever and a rash is suggestive of hypersensitivity reactions. Eosinophilia, normocellular or hypocellular bone marrow and concomitant depression of red cell and platelet synthesis have previously been reported. ${ }^{1-5}$

\section{QUESTION 2}

Patients who develop cloxacillin-induced agranulocytosis tend to share some common characteristics. ${ }^{1-5}$ They all suffer from serious staphylococcal infections such as infective endocarditis and osteomyelitis. The cloxacillin therapy is usually prolonged, with daily doses of 8-12 g. The average duration of treatment before agranulocytosis appeared is around 23 days. ${ }^{4}$

The risk factors for neutropenia $\left(\leqslant 2.0 \times 10^{9} / 1\right)$ after a prolonged course of intravenous cloxacillin were studied in 128 adults with serious staphylococcal infections. ${ }^{4}$ The 22 patients $(17.2 \%$ ) who developed neutropenia received significantly longer treatment (23.2 \pm 7.4 vs $11.4 \pm 12.2$ days) and a higher

1 Westerman EL, Bradshaw MW, Williams TW Jr Agranulocytosis during therapy with orally administered cloxacillin. Am f Clin Pathol 1978; 69: 559-60.

2 Shah I, Kumar KS, Lerner AM. Agranulocytosis associated with chronic oral administration of cloxacillin for suppression of staphylococcal oesteomyelitis. Am $₹$ Hematol 1982 12: 203-6.

3 Miro JM, Gatell JM, Moreno A, Mensa J, Roca J, Garcia San Miguel J. More on penicillin-induced leukopenia [letter]. N Engl f Med 1983; 308: 901-2.
Risk factors for cloxacillin-induced agranulocytosis

- severe staphylococcal infections

- a prolonged course

- a high total dose

- a low pretreatment neutrophil count

\begin{tabular}{|l|}
\hline Summary point \\
\hline $\begin{array}{l}\text { Because of its life-threatening nature, physicians } \\
\text { should be aware of the risk factors for } \\
\text { cloxacillin-induced agranulocytosis, particularly } \\
\text { when using this antibiotic to treat severe } \\
\text { staphylococcal infections }\end{array}$
\end{tabular}

total dose $(241.5 \pm 86$ vs $105.9 \pm 123.5 \mathrm{~g})$, compared with patients without a neutropenia. After adjusting for confounding factors, a total cloxacillin dose of $\geqslant 150 \mathrm{~g}$ was associated with the development of neutropenia.

In a prospective study of neutropenia due to high doses of cloxacillin and other $\beta$-lactam antibiotics, ${ }^{5}$ patients with neutropenia differed from others in having a lower pretreatment neutrophil count (3.2 vs 10.4).

\section{Prognosis}

The neutrophil count recovers quickly on stopping cloxacillin. An average of 4.6 days was reported in one study. ${ }^{3}$

\section{Final diagnosis}

Cloxacillin-induced agranulocytosis

Keywords: agranulocytosis, cloxacillin, Staphylococcus aureus, septicaemia

4 Gatell JM, Rello J, Miro JM, Martinez JA, Soriano E, San Miguel Garcia J. Cloxacillin-induced neutropenia [letter]. $\mathcal{F}$ Infect Dis 1986; 154: 372.

5 Olaison L, Alestig K. A prospective study of neutropenia induced by high doses of beta-lactam antibiotics. $₹$ Antimicrob Chemother 1990; 25: 449-53. 